\title{
Desarrollo Territorial, gobernanza y Denominaciones de Origen: El estudio de las "D.O.s." vitivinícolas de Méntrida, Mondéjar y Uclés
}

\author{
Silvia Freitas CAETANO \\ Departamento de Geografía Humana \\ Universidad Complutense de Madrid \\ sfcaetano@ucm.es \\ Consuelo Del CANTo Fresno \\ Departamento de Geografía Humana \\ Universidad Complutense de Madrid \\ ccantofr@ucm.es
}

Recibido: 1 de octubre del 2013

Enviado a evaluar: 8 de enero del 2014

Aceptado: 30 de abril del 2014

\section{RESUMEN}

El presente artículo se enmarca en el estudio de las denominaciones de origen desde la perspectiva del desarrollo territorial. El artículo investiga sobre el papel de las redes socioinstitucionales en el apoyo a estas figuras de calidad, y en la generación de procesos de buena gobernanza, pieza clave en el desarrollo territorial. Para ello, se analizan tres denominaciones de origen vitivinícolas ubicadas en Castilla-La Mancha, Méntrida, Mondéjar y Uclés, insertadas en un contexto regional e institucional similar, pero con realidades distintas. Por su perspectiva constructivista, los resultados de este trabajo, reflejan la realidad a partir de las visiones contrastadas de los propios actores del territorio.

Palabras clave: Desarrollo Territorial, Denominaciones de Origen, gobernanza local, gobernanza territorial, redes socioinstitucionales.

\section{Territorial Development, governance and Protected Designation of Origin: case study of the "P.D.O.s." Méntrida, Mondéjar and Uclés.}

\begin{abstract}
This article focuses on the study of the Protected Designation of Origins from the territorial development perspective. The paper investigates the role played by socio-institutional networks in the support to these quality schemes and in the promotion of good governance processes, a key concept in territorial development. To do so, three different Spanish wine Protected Designation of Origins are analysed, Méntrida, Mondéjar and Uclés. They are located in the Autonomous Region of Castilla-La Mancha, and they have similar regional and institutional contexts, but different realities. Given to its constructivist
\end{abstract}


perspective, the results of this study reflect the reality from the contrasting perspectives of the agents of the territory.

Key words: Territorial Development, Protected Designation of Origin, local governance, territorial governance, socio-institutional networks.

Développement territorial, la gouvernance et les appellations d'origine: l'étude de vin "A.O.C." Méntrida, Mondejar et Uclés.

\section{RÉSUMÉ}

Cet article se concentre sur l'étude des appellations d'origine dans la perspective du développement territorial. Le document examine le rôle des réseaux socio-institutionnels à l'appui de ces systèmes de qualité, et la génération de processus de bonne gouvernance, clé dans le développement territorial. Pour ce faire, nous analysons trois appellations d'origine situés en Castilla-La Mancha, Méntrida, Mondejar et Uclés, inséré dans un contexte régional et institutionnel semblable, mais des réalités différentes. Sur la perspective constructiviste, les résultats de cette étude reflètent la réalité des visions contrastées des acteurs du territoire.

Mots clés: Développement territorial, les appellations d'origine, la gouvernance locale, la gouvernance territoriale, les réseaux socio-institutionnels.

\section{INTRODUCCIÓN}

El estudio de las marcas de calidad territorial, como las denominaciones de origen (DO) o las indicaciones geográficas (IG) son objeto de atención de múltiples enfoques y disciplinas. Desde la Geografía, numerosos estudios tratan de relacionar la existencia de estas marcas de calidad con los procesos de Desarrollo Territorial Rural (en adelante, DTR) enfoque que adopta el presente artículo.

Muchos son los factores que juegan un papel importante en el buen funcionamiento de estas figuras y en su contribución al desarrollo de los territorios que las alojan. Uno fundamental es la existencia de un tejido institucional capaz de apoyar estos procesos, responsable de la buena gobernanza, pieza clave para el desarrollo de los espacios rurales desde el enfoque territorial. Es este factor mencionado, el objeto de interés del presente artículo, que investiga la participación del tejido institucional regional en la marcha de tres denominaciones de origen vitivinícolas pertenecientes a la Comunidad Autónoma castellano-manchega.

El articulo está dividido en cinco partes, la primera aborda la definición de Desarrollo Territorial Rural, gobernanza y denominaciones de origen así como la relación entre estos tres conceptos; la segunda presenta brevemente el contexto en el que se insertan las tres denominaciones de origen estudiadas; la tercera y la cuarta describen y analizan los resultados obtenidos, desde el enfoque metodológico adoptado, sobre el apoyo institucional que reciben las tres denominaciones de origen y la quinta resume las conclusiones obtenidas. 


\section{DESARROLLO TERRITORIAL RURAL, GOBRNANZA Y DENOMINACIONES DE ORIGEN}

\subsection{DESARROLLO TERRITORIAL RURAL}

El estudio de las Denominaciones de Origen desde el enfoque del Desarrollo Territorial requiere precisar este concepto.

El DTR surge en las últimas décadas como alternativa al modelo de desarrollo que privilegia la perspectiva económica por encima de cualquier otra. Este aporta la problemática del territorio y pone el foco de interés en la relación entre los agentes y su territorio, en el que formulan y realizan sus proyectos de desarrollo. Se asocia a su vez a otros conceptos como identidad, gobernanza, partenariado o acción colectiva, entendiendo que es un concepto de carácter fundamentalmente sociopolítico y no exclusivamente económico.

En todas sus definiciones, incluso aquellas establecidas a partir de la experiencia práctica (Shejtman y Berdegué, 2004), el principio básico del DTR es la generación de dinámicas espaciales más equilibradas y sostenibles, que impliquen un mayor poder de decisión de los actores locales. Se trata de un proceso que comprende a la vez una transformación productiva e institucional. La productiva busca la dinamización sostenible de la economía local, y su articulación con los mercados mundiales de forma competitiva; la institucional apoya y fomenta la interacción y formación de redes internas y externas al territorio y el aumento de las oportunidades de participación de la población local en todos estos procesos y redes (Schejtman y Ramírez, 2004).

En el contexto del DTR, las Denominaciones de Origen, por sus características, puede servir de herramienta para el desarrollo territorial en tanto que tienen como objetivo la transformación productiva desde un modelo que busca anclar la producción al territorio, logrando la territorialización de un recurso local específico. Una DO implica la existencia de un recurso único, no imitable y vinculado a una localidad específica. Esa diferenciación se relaciona no sólo con el producto en sí, también con elementos del territorio en el que es producido, como su paisaje, su cultura, su patrimonio histórico, su saber-hacer, etc.

Desde esta perspectiva, las DOs entran en el Desarrollo Territorial Rural a través de dos procesos complementarios: permiten la calificación del producto local; pero también permiten la creación de dinámicas y la puesta en valor del propio territorio.

La transformación productiva debe venir acompañada de una transformación institucional que propicie la buena gobernanza y con ello la valorización del territorio en su conjunto, desde el establecimiento de un marco jurídico eficaz, la promoción de actuaciones de apoyo a estas figuras hasta la creación de redes. Es ahí donde DTR, DO y gobernanza se alían. 


\subsection{LA GOBERNANZA}

Gobernanza, es otro de los términos, como el DTR que se emplea en la actualidad con mucha frecuencia y no de manera unánime, ya que se encuentran definiciones muy variadas al respecto. Una de las más empleadas se asocia con el 'buen gobierno', que alude al papel de las instituciones, a su forma de actuación, su representatividad legal, su transparencia, legitimidad, credibilidad y equidad, además de la efectividad y eficiencia de sus acciones (Romero y Farinós, 2011). Esta noción de gobernanza está presente particularmente en programas de desarrollo llevados a cabo en países con barreras democráticas.

Otras definiciones que amplían el concepto de 'buen gobierno' incluyen la forma que el poder es ejercido, cómo son tomadas las decisiones, quién decide y cómo decide, y cómo los ciudadanos intervienen, o pueden intervenir en este proceso (Romagosa et al., 2012; Romero y Farinós, 2011). La gobernanza se traduce en "un conjunto complejo de actores e instituciones, que no pertenecen solamente a la esfera gubernamental, y que es capaz de traducir la interdependencia entre el poder y las instituciones vinculadas a la acción colectiva ${ }^{1 "}$ (Lazarev, 2009, p. 198). En esta noción de gobernanza, las instituciones componen la red local en un entramado de actores que coordinan iniciativas públicas y privadas con una finalidad común, compartida por la comunidad local.

Es imposible hablar de un verdadero proceso de desarrollo territorial sin gobernanza, ya que en la raíz de estos conceptos está la idea de desarrollo integrado, de participación, de construcción de objetivos "desde abajo", de apropiación del proceso de desarrollo por la sociedad civil y de coordinación de actores, condiciones que no se pueden llevar a cabo sin una verdadera articulación entre actores privados y públicos, y sin la distribución equitativa del poder de decisión.

La gobernanza se relaciona con las DOs en la medida en que la creación de esta figura hace necesario el establecimiento de algunas condiciones básicas que permitan el reconocimiento y el apoyo a esta figura como la creación de un marco jurídico que posibilite el reconocimiento y la protección de los derechos de propiedad colectiva sobre la DO. De la misma manera es importante la puesta en marcha de un conjunto de políticas capaces de apoyar a los actores en las diversas fases de la constitución y puesta en marcha de una DO, de promover relaciones comerciales más equilibradas, de fomentar la creación de redes, de redistribuir el valor a lo largo de la cadena y de promover los valores culturales y la preservación ambiental (Vandecandelaere et al.,2010)

En una DO, el papel que pueden desempeñar las instituciones - entendidas en su sentido más general, considerando tanto las organizaciones como las reglas tácitas, normas y convenciones presentes en cada territorio - se relaciona con la creación de dinámicas de buena gobernanza local y territorial. Esto ocurre en la medida en que,

\footnotetext{
${ }^{1}$ Traducido del francés por los autores
} 
poniendo en práctica el marco jurídico y las acciones de apoyo a la figura de calidad, son capaces de fomentar las redes de cooperación, la participación local en los procesos decisorios y la colaboración entre actores de diferentes ámbitos, como social, empresarial y gubernamental. Las instituciones de carácter gubernamental se encuentran en una posición privilegiada para fomentar la buena gobernanza dada su visión holística del territorio y las posibilidades que disponen.

\subsection{DO Y GOBERNANZA: GOBERNANZA SECTORIAL Y GOBERNANZA TERRITORIAL}

Se entiende por DO la denominación geográfica de un país, de una región o de una localidad que sirva para designar un producto del mismo y cuya calidad o característica se deben exclusiva o esencialmente al medio geográfico, comprendidos los factores naturales y los factores humanos ${ }^{2}$. Bajo cada sello existe una serie de normas y parámetros publicados en un registro único, y que deben ser seguidas por los elaboradores que deseen vender sus productos bajo este sello de calidad. Las Denominaciones de Origen Protegidas (DOP) asocian el producto a su sitio de origen, ya que para la obtención del sello es necesario que, además de características específicas y reputación asociada a una zona determinada, todas las etapas de producción se lleven a cabo en dicha zona ${ }^{3}$.

Por la propia definición de DO, esta figura debe partir de una acción colectiva, de un conjunto de actores que comparten una misma visión, y establecen las características que define un producto, las condiciones de producción y las reglas comunes de concesión de los derechos para utilizar la denominación.

Gobernanza y DO se asocian a lo largo de todo el proceso de constitución y desarrollo de la figura de protección. En una primera etapa se dan procesos de cooperación y participación entre los agentes locales más directamente vinculados a la figura de protección, como productores, elaboradores, envasadores. Es lo que algunos autores denominan gobernanza local o sectorial de filière, (Sanz Cañada, 2009), cuando la DO constituye en torno a sí una red de carácter económicoinstitucional local, resultado de las acciones colectivas de promoción y marketing, de

${ }^{2}$ Esta definición clásica proviene del Arreglo de Lisboa (1958), acuerdo internacional que pretendía el reconocimiento mutuo de las denominaciones de calidad (cit. López, 1996: 43 p.). El énfasis dual (calidad o característica) para la creación de una DO se mantiene tanto en la Resolución de Madrid (ECO/92) sobre DO e Indicaciones Geográficas como en el «Acuerdo sobre los aspectos de los derechos de propiedad intelectual relacionados con el comercio» (Marraquech,15/4/94), justificando este último la protección «cuando determinada calidad, reputación u otra característica del producto sea imputable fundamentalmente a su origen geográfico» (art.22, cit. Milans del Bosch, 1994: 165 p.).

3 REGLAMENTO (CE) No 510/2006 DEL CONSEJO de 20 de marzo de 2006 sobre la protección de las indicaciones geográficas y de las denominaciones de origen de los productos agrícolas y alimenticios. Diario Oficial de la Unión Europea 31.3.2006 
formación de capital humano, de redes de comercialización, de creación de organizaciones a escala local impulsadas por el Consejo Regulador.

La consolidación de la DO puede impulsar otros procesos añadidos a los descritos que son también de una gran importancia para los territorios en los que se asienta una Denominación de Origen. Estos procesos complementarios se pueden englobar en el término de gobernanza territorial, un concepto que relaciona la gobernanza a la idea del territorio como un recurso a ser movilizado, como un activo específico que puede generar beneficios colectivos o externalidades positivas (Sanz Cañada, 2009). Bajo este enfoque, la gobernanza se relaciona a una red socio-institucional que abarca tanto actores locales y directamente vinculados a la actividad productiva de la DO, como actores externos y de instituciones de diferentes ámbitos territoriales. Esta red puede ser capaz, a través de actuaciones colectivas y complementarias, de generar un beneficio para el territorio en su totalidad, incluyendo no sólo las actividades de la elaboración del producto con la etiqueta DO, sino los demás aspectos como el patrimonio histórico, cultural, natural y paisajístico de la zona, dinamizando y expandiendo los beneficios a otros sectores de la actividad económica, como el turismo, la hostelería, la gastronomía, etc., propiciando con ello la puesta en valor del territorio en su conjunto.

Así, la gobernanza territorial tiene como objetivo que el territorio demarcado por una DO esté involucrado en un proceso de desarrollo común, y es la expresión de la gobernanza más íntimamente vinculada al DTR.

\subsection{DO Y REDES SOCIOINSTITUCIONALES}

Desde hace ya más de dos décadas, muchos investigadores interesados en el desarrollo territorial destacan la importancia de las redes locales de cooperación al considerar que contribuyen a la creación de un entorno social que propicia el dinamismo económico y puede favorecer los procesos que conducen a la construcción de territorios. Las redes se convierten así en un paradigma asociativo o paradigma de red que vincula la existencia de relaciones con el dinamismo y la competitividad de los territorios, incorporándose su análisis de forma destacada al repertorio de herramientas disponibles para la investigación socioeconómica (Camagni, 1991; Cooke-Morgan, 1993; Casti, 1995; Koschatzky, 2002; Méndez, 2002; Salom y Albertos, 2009; Caravaca y González, 2009)

Los procesos de gobernanza en una DO, sea local o territorial, están íntimamente ligados al establecimiento de redes entre los diferentes agentes del territorio, redes que facilitan extraer el máximo beneficio económico, político, social y científico a toda la colectividad de actores en el funcionamiento de esta figura de calidad.

La formación de las redes en el marco de una DO está determinada por la estrategia adoptada por los actores del territorio. Cuando la estrategia de actuación colectiva se limita a la certificación de productos de calidad, estas redes tienen dimensiones más reducidas, abarcando solo a los actores directamente implicados. Cuando se opta por la comercialización en mercados más globales, las redes locales se extienden a otros actores como científicos, investigadores, técnicos de certificación, 
degustadores, etc. (Fonte, 2000). Si la estrategia puesta en marcha adopta el propio territorio como un activo específico, para ser valorado en su conjunto, las redes formadas pueden ser de mayor complejidad, en tanto que implican una mayor diversidad de actores, de múltiples ámbitos territoriales y sectoriales. Esta complejidad aumenta aún más cuando se vislumbra una proyección global de este territorio.

En lo relativo al establecimiento y al papel de las redes sociales en formaciones espaciales productivas, el estudio de una DO se interesa por los distintos tipos de redes: a) Redes de colaboración empresarial, formada sobre todo por los actores económicos locales relacionados con la producción, elaboración, servicios, comercialización, cuya efectividad reside en la capacidad de obtener economías de escala, mayor aprendizaje colectivo y mejor aprovechamiento de los recursos. Estas redes posibilitan los procesos de gobernanza local; b) Redes socioinstitucionales y empresariales para la innovación, en las que se establecen sinergias entre recursos públicos y privados, paso intermediario para alcanzar la gobernanza territorial, y c) Redes socioinstitucionales, directamente vinculadas con nuevas formas de gobernanza en los territorios.

El presente artículo se interesa particularmente por estas últimas, las redes socioinstitucionales y hace alusión a las redes de colaboración empresarial dentro del territorio DO.

\section{CONTEXTO EN EL QUE SE INSERTEN LAS TRES DOS ESTUDIADAS}

Las tres denominaciones vitivinícolas analizadas pertenecen a la Comunidad Autónoma de Castilla-La Mancha, diferentes entre sí y al mismo tiempo con rasgos generales semejantes asociados a las características de esta región.

Tabla 1. Datos agrarios de las Zonas Rurales definidas en el marco del Programa de Desarrollo Rural Sostenible 2010-2014.

\begin{tabular}{|r|c|c|c|}
\hline & $\begin{array}{c}\text { Nivel de ocupa- } \\
\text { ción en la activi- } \\
\text { dad agraria } \mathbf{2 0 1 1} \\
(\%)\end{array}$ & $\begin{array}{c}\text { Densidad } \\
\text { población } \\
\mathbf{2 0 1 1} \\
\text { (hab/km²) }\end{array}$ & $\begin{array}{c}\text { Tasa de } \\
\text { substitución } \\
\mathbf{2 0 1 1}(\mathbf{\%})\end{array}$ \\
\hline $\begin{array}{r}\text { Tajo Medio (Méntrida) } \\
\text { Tajo-Tajuña (Mondéjar) }\end{array}$ & $\mathbf{6 , 5}$ & 53 & $\mathbf{1 4 6 , 8}$ \\
\hline Sierra y Mancha Conquense (Uclés) & 10,2 & 13 & 111,7 \\
CC AA Castilla - La Mancha & 5 & 12 & 131,5 \\
España & 2 & 27 & 140,5 \\
\hline
\end{tabular}

Fuente: Elaboración propia con datos del Instituto Nacional de Estadística INE (2011), Ministerio de Agricultura, Alimentación y Medio Ambiente. Fondo Español de Garantía Agraria (2011). 
La Comunidad Autónoma de Castilla- La Mancha es una región de tradición agrícola de marcado carácter rural, con presencia de zonas rurales profundas, aquejadas por el envejecimiento de población, la despoblación, bajos niveles de renta per capita y con acusada dependencia de la agricultura como base material de su economía. La Tabla 1 resume los principales indicadores de las zonas rurales en las que se ubican cada denominación estudiada. El carácter rural expresado por estos datos puede ser aún más marcado en las zonas rurales más deprimidas.

Por sus características y grados de ruralidad, las zonas rurales castellanomanchegas han estado normalmente incluidas en las áreas prioritarias en los programas de desarrollo rural de la Unión Europea y de España. Según la tipología de espacios rurales creada por el Ministerio de Agricultura, Alimentación y Medio Ambiente (MAGRAMA) para dirigir sus políticas de desarrollo rural, el $89 \%$ del territorio de la Comunidad Autónoma de Castilla-La Mancha ha sido clasificado como zonas rurales. De estas, el $48 \%$ son clasificadas como espacios a revitalizar, un $45 \%$ son zonas rurales intermedias y el $7 \%$ restantes, zonas periurbanas.

Las tres denominaciones de origen estudiadas se ubican en áreas rurales deprimidas, aunque con diferencias entre ellas. La Tabla 2 presenta el tipo de espacio rural que predomina en cada zona y la prioridad de actuación en programas de desarrollo rural.

Tabla 2. Clasificación de las Denominaciones de Origen según tipología de espacios rurales.

\begin{tabular}{r|ccc}
\hline \multicolumn{1}{|c|}{ Zona Rural } & DO - Provincia & Calificación & Nivel Prioridad \\
\hline Tajo Medio & Méntrida - Toledo & Periurbana & Tercer nivel \\
Tajo-Tajuña & Mondéjar - Guadalajara & Intermedia & Segundo nivel \\
Sierra y Mancha Conquense & Uclés - Cuenca & A revitalizar & Primer nivel \\
\hline
\end{tabular}

Fuente: Elaboración propia con datos del Programa de Desarrollo Rural Sostenible 2010-2014

Pese a su alto grado de ruralidad, todos los territorios adscritos a las DOs se encuentran relativamente cerca de la aglomeración madrileña, compartiendo límites con la Comunidad Autónoma de Madrid (Figura 1).

La DO Méntrida está ubicada en la provincia de Toledo. Es una denominación relativamente madura, la más antigua de las tres zonas estudiadas, y fue fundada con la intención de proteger la especificidad de sus caldos de alto contenido alcohólico, que en origen, tenía gran éxito en Madrid.

Mondéjar es una DO muy pequeña de la provincia de Guadalajara, de fundación relativamente reciente, establecida como un intento de revitalizar la actividad agraria en la zona. Partió como iniciativa de una bodega en particular contando con el estímulo del poder público en su creación.

La DO Uclés es la más nueva de las tres zonas, su territorio se reparte entre las provincias de Cuenca y Toledo. Ha surgido como una estrategia para diferenciar los 
vinos del territorio de Uclés de los vinos de la DO Mancha, cuyas áreas se superponen. La Tabla 3 recoge los principales datos de cada DO estudiada.

Figura 1. Mapa de las tres Denominaciones de Origen estudiadas.

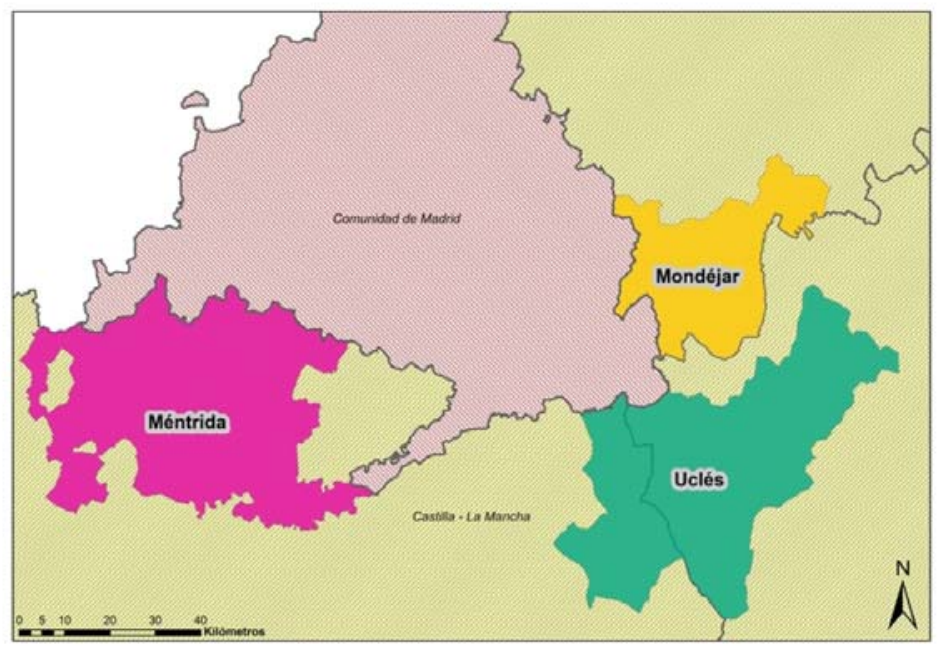

Fuente: Elaboración propia.

Tabla 3. Datos básicos de las Denominaciones de Origen.

\begin{tabular}{r|cccc}
\hline DO & Año Fundación & Bodegas Inscritas & N $^{0}$ viticultores & Superficie inscrita \\
\hline Méntrida & 1976 & 28 & 1.443 & 5.581 has \\
\hline Mondéjar & 1997 & 2 & 300 & 500 has \\
\hline Uclés & 2006 & 5 & 228 & 1.700 has \\
\hline
\end{tabular}

Fuente: Elaboración propia con datos del Ministerio de Agricultura, Alimentación y Medio Ambiente (campaña 2010/2011)

La Comunidad Autónoma de Castilla-La Mancha cuenta con un entramado institucional bastante denso en materia de agricultura, desarrollo rural y vitivinicultura, actividad que tiene gran representatividad en el territorio. Se ha identificado un importante número de instituciones que atiende a las tres zonas 
estudiadas, no solamente en el ámbito autonómico, sino también en el local. Todos estos órganos institucionales desarrollan funciones diversas, tanto para el sector vitivinícola como para otros sectores: investigación, formación, apoyo a la comercialización y exportación, entre otros.

En este contexto se ha realizado la investigación que se presenta en estas líneas, que tiene como objetivo explicar, a través de la realización de entrevistas a los Consejos Reguladores (CRDO) y a los principales órganos Institucionales, así como de encuestas a bodegas adscritas a la DO, cómo es la actuación institucional en el apoyo a las DOs, según los propios actores de las DOs y según la visión que las instituciones tienen de sí mismas. El trabajo de campo ha permitido, además, identificar y cartografiar algunas de las redes que se dibujan en el territorio, generando una buena herramienta de descripción que facilita el análisis de la presencia o ausencia de los procesos que pueden conducir a la gobernanza local y territorial en los territorios DO analizados.

\section{LA CONFRONTACIÓN DE VISIONES EN LAS TRES DOs ESTUDIADAS}

El constructivismo geográfico se muestra como una herramienta metodológica adecuada para la investigación planteada. Su aplicación ha permitido una interpretación de la realidad estudiada a partir de los diferentes puntos de vista de los actores implicados sobre su vivencia cuotidiana. En este enfoque, no existe una realidad objetiva, sino construida por los diferentes sujetos, que la significan y constituyen a partir de las interacciones entre ellos y el medio que les rodea (Hernández de La Cruz, 2011). La investigación también parte de la noción de territorio como una obra social colectiva (Lindón, 2007), y el territorio rural como una construcción social.

Figura 2. La investigación constructivista.

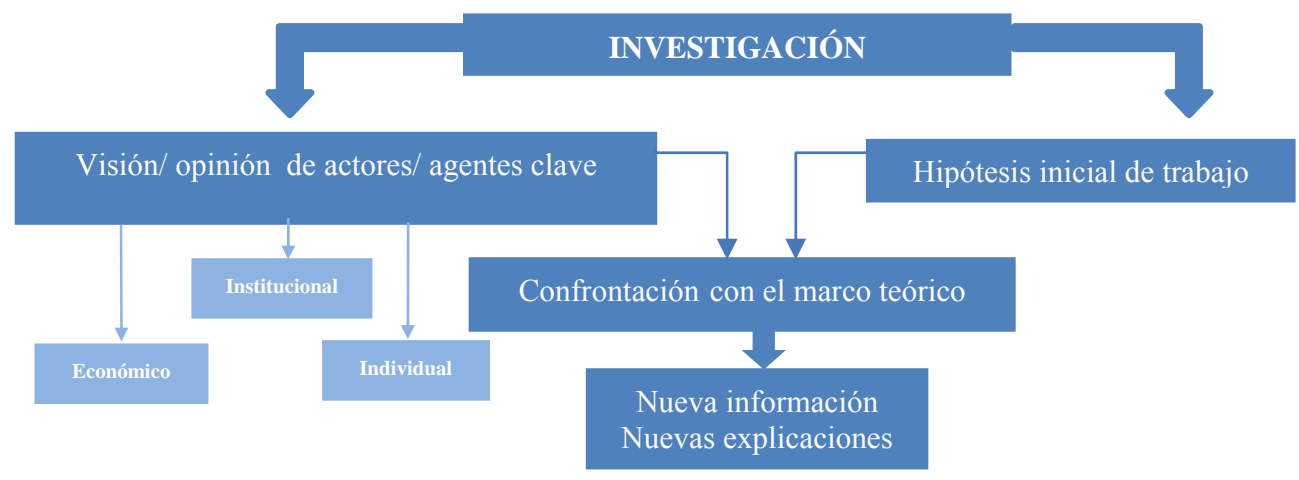

Fuente: Elaboración propia. 
Desde el enfoque metodológico adoptado, el material de estudio recopilado consta de entrevistas semi-estructuradas en profundidad y encuestas (Tabla 4). Las instituciones entrevistadas fueron elegidas entre las que los agentes mencionaban más recurrentemente durante el trabajo de campo y con las que aquéllos expresaban algún tipo de relación o el interés por las actividades desarrolladas. Las encuestas fueron realizadas a la totalidad de las bodegas adscritas a las tres denominaciones de origen.

El contenido de las entrevistas ha permitido contrastar las visiones de los diferentes agentes implicados en el funcionamiento de las tres denominaciones de origen. El material de las encuestas ha tenido dos funciones: una, identificar las relaciones que las bodegas mantienen con los órganos del entorno institucional y con el conjunto de las demás bodegas, y otra, hacer un análisis de las redes que parecen fraguarse, cartografiándolas con el programa UCINET ${ }^{4}$, herramienta que permite representar la frecuencia e intensidad de las relaciones de las bodegas con su entorno institucional en los territorios adscritos a las DOs (Figuras 4, 5, 6, 7, 8 y 9).

Tabla 4. Información sobre el material de estudio.

\begin{tabular}{|c|c|}
\hline $\begin{array}{l}\text { Entrevistas semi-estructuradas en profun- } \\
\text { didad }\end{array}$ & Encuestas (85\% de respuestas) \\
\hline $\begin{array}{l}\text { CRDO Méntrida - Consejo Regulador de la } \\
\text { DO Méntrida }\end{array}$ & $\begin{array}{l}\text { Bodegas adscritas a la DO Méntrida }(60 \% \text { de } \\
\text { respuestas) }\end{array}$ \\
\hline $\begin{array}{l}\text { CRDO Mondéjar - Consejo Regulador de la } \\
\text { DO Mondéjar }\end{array}$ & $\begin{array}{l}\text { Bodegas adscritas a la DO Mondéjar (100\% de } \\
\text { respuestas) }\end{array}$ \\
\hline $\begin{array}{l}\text { CRDO Uclés - Consejo Regulador de la DO } \\
\text { Uclés }\end{array}$ & $\begin{array}{l}\text { Bodegas adscritas a la DO Uclés }(100 \% \text { de } \\
\text { respuestas) }\end{array}$ \\
\hline $\begin{array}{l}\text { Consejería de Agricultura de la Junta de } \\
\text { Castilla-La Mancha: Dirección General de } \\
\text { Infraestructuras y Desarrollo Rural y Servicio } \\
\text { de Ordenación Alimentaria y Calidad Dife- } \\
\text { renciada }\end{array}$ & \\
\hline $\begin{array}{l}\text { IVICAM - Instituto de La Vid y el Vino de } \\
\text { Castilla-La Mancha }\end{array}$ & \\
\hline $\begin{array}{l}\text { IPEX - Instituto de Promoción Exterior de } \\
\text { Castilla-La Mancha }\end{array}$ & \\
\hline $\begin{array}{l}\text { FTV - Fundación Castilla-La Mancha Tierra } \\
\text { de Viñedos }\end{array}$ & \\
\hline
\end{tabular}

${ }^{4}$ Programa desarrollado por Analytic Technologies de la Universidad de Harvard, MA, por Borgatti, S.P., Everett, M.G. y Freeman, L.C. Versión utilizada 6.392, de mayo de 2012. 


\subsection{LA DO MÉNTRIDA}

\subsubsection{LA PERCEPCIÓN DE LA DO MÉNTRIDA SOBRE SUS INSTITUCIONES}

Como resultado de la entrevista del CRDO, surgen una serie de críticas a las instituciones, especialmente a las autonómicas que son las más mencionadas y las consideradas más presentes por el entrevistado. Las instituciones locales no fueron casi mencionadas.

En líneas generales, la entrevista con el CRDO de Méntrida ha demostrado la poca satisfacción de esta denominación con la actuación institucional. Estas insatisfacciones se traducen en tres críticas principales.

La primera de ellas trata del alejamiento de muchas medidas adoptadas a partir de escalas administrativas más altas, a la realidad local. Lo que se traduce en que las medidas adoptadas están planteadas desde las DOs de mayor influencia de la CCAA e ignoran la realidad de las denominaciones pequeñas, así como las peculiaridades que pueden existir en la gran variedad de denominaciones existentes en el territorio castellano-manchego.

La segunda se refiere a la falta de efectividad en las actuaciones llevadas a cabo por las instituciones presentes, según lo entiende el CRDO. Esta falta de efectividad es identificada en las acciones de burocracia exigidas por determinados órganos, en las actuaciones institucionales caras, de poco alcance y provecho para las DOs y en los problemas internos de coordinación y malas prácticas de algunos organismos.

La tercera crítica manifiesta que las ayudas y subvenciones aplicadas a las DOs resultan contradictorias, y se considera que algunas de ellas incluso ponen en peligro la existencia de la propia DO. Entre los ejemplos enumerados, están las ayudas de reestructuración del viñedo que son vistas como una amenaza a la existencia de las vides antiguas, sobre todo de la variedad garnacha, que son consideradas como el hecho diferencial de la denominación. Además, entienden que el arranque estimula la disminución de la superficie de viña, y prioriza la financiación de aquellos viticultores que se retiran de la actividad en detrimento de las ayudas a los que se quedan, y resisten a las adversidades actuales del sector en la zona.

\subsubsection{LA PERCEPCIÓN DE LA DO MÉNTRIDA SOBRE SI MISMA}

De la entrevista con la CRDO, también surgieron críticas sobre su situación interna. En general, hay un dominio del pesimismo, y el único elemento a favor manifestado en la entrevista fue el papel que tienen algunas bodegas pioneras en la dinamización de la actividad y de la marca DO en algunos mercados, pero que representan poco más que el $15 \%$ de las empresas. Se señalaron los siguientes aspectos:

a) La pérdida de superficie de viñedo por abandono o por arranque, muchas veces subvencionado. 
b) El envejecimiento de los viticultores, la baja tasa de incorporación de jóvenes y la prevalencia de viticultores a tiempo parcial, cuyos intereses en invertir en la calidad son bastante limitados (falta de interés/ tiempo)

c) La poca capacidad de movilización local en torno a la figura de la DO, ya que muchas bodegas no apuestan por ello.

d) La falta de estrategia comercial de casi la totalidad de las bodegas, que en su mayoría son cooperativas compuestas por socios en edad avanzada o de dedicación parcial a la actividad. El perfil de las cooperativas es bastante típico, centrado en la venta a granel, con poco interés en los vinos de calidad, y ausencia de estrategias renovadas de mercado y comercialización.

\subsubsection{LAS BODEGAS DE LA DO MÉNTRIDA Y SUS RELACIONES INSTITUCIONALES}

De las encuestas realizadas a las bodegas, y a través del análisis de redes sociales, se identificaron tres grupos de empresas según la naturaleza de las relaciones que establecen con los distintos agentes del entorno: un primer perfil lo componen las bodegas que se relacionan con los órganos locales y con aquellos organismos a los que están obligados en el ejercicio de sus tareas (Figura 3: bodegas 2, 3, 6, 10, 11, 13 y 16, en color verde). Un segundo grupo lo componen aquellas bodegas que establecen relaciones con los órganos responsables de las exportaciones y las Universidades (Figura 3: bodegas 1, 4, 5, 8 y 9, en color amarillo), y que coinciden con las más innovadoras. $\mathrm{Y}$ un tercer grupo que establecen relaciones con los órganos de los dos tipos presentes en los grupos anteriores (Figura 3: bodegas 7, 12, 14 y 15, en color rojo), aunque sus redes con estos órganos no son tan densas como en el grupo 1, o el grupo 2. La expresión de estos tres comportamientos se puede ver en la Figura 3.

Los órganos institucionales con los que se mantiene más contacto aparecen en el centro del gráfico.

Este gráfico permite identificar que el segundo grupo de bodegas, cuyas relaciones priorizan las exportaciones y la innovación, corresponde solo a un $19 \%$ de las bodegas. Lo que muestra que en la Denominación hay un conjunto de bodegas que son su motor, su dinamizador, y las demás empresas son llevadas por esta dinámica y se benefician de ella. El análisis de redes sociales corrobora la opinión dada por el Consejo Regulador, sobre cuáles son las bodegas de mayor dinamismo, que tratan de impulsar la Denominación de Origen. 
Figura 3. Red de relaciones DO Méntrida y órganos Institucionales. Análisis de Redes Sociales (UCINET).

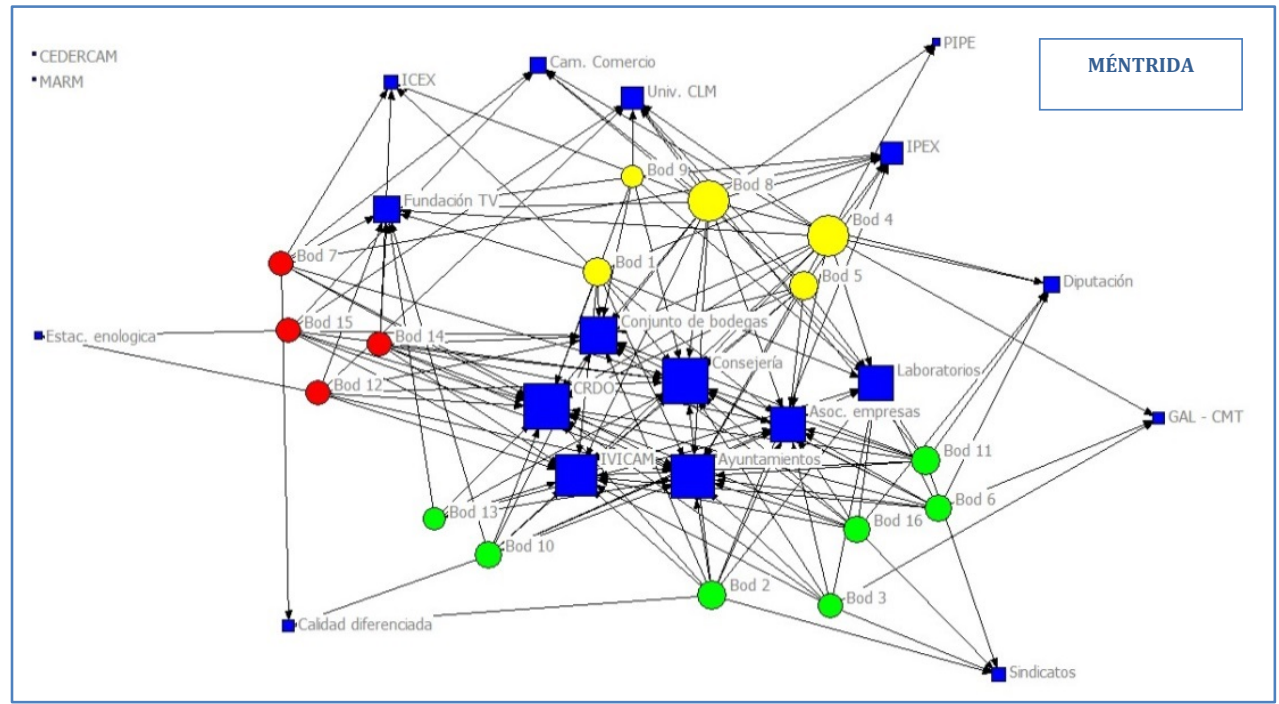

Fuente: Elaboración propia.

Utilizando la misma herramienta UCINET, y las mismas encuestas, se han cartografiado las relaciones según diferentes tipos (Figura 4). A partir de estos gráficos, se ha identificado lo siguiente:

a) Algunas bodegas consideran el IVICAM como prestador de servicios (análisis y calificación de vinos), función que no está incluida en las finalidades de este órgano. No obstante, siendo la formación una de las principales funciones del Instituto, son pocas las bodegas que mantienen relaciones de capacitación con esta institución (37,5\% del total encuestado).

b) La Consejería de Agricultura es mencionada muchas veces en las relaciones de trámites y regulación, y es la figura central en las subvenciones; no obstante, apenas aparece en el gráfico de asesoría, y no está presente en el gráfico de trabajo conjunto. Este resultado pone de manifiesto que la mayoría de las bodegas no percibe a la Consejería de Agricultura con funciones de asesoría, cooperación y actuación conjunta, pese a que sean funciones importantes de este órgano, además de las de trámites y subvenciones.

c) El Consejo Regulador aparece con más frecuencia en las relaciones de trámites y regulación que en las relaciones de trabajo conjunto. Aunque muchas de las bodegas contemplan actuaciones conjuntas con este órgano, la gran mayoría lo percibe como una figura institucional de trámites y regulación de la actividad.

De los gráficos que componen la Figura 4, llama la atención la visión equivocada que tienen las bodegas sobre las funciones y objetivos institucionales. No tienen 
suficiente información sobre cómo relacionarse, o para qué hacerlo, o qué pedirles. Las relaciones establecidas no dan solución a las verdaderas cuestiones o necesidades que tienen las bodegas. Esto se observa en las relaciones porque las bodegas ven en las instituciones funciones que no son sus principales, o que no pertenecen a su ámbito de actuación. Además, en muchos casos no identifican las verdaderas funciones institucionales. Por la falta de información, las bodegas pierden las oportunidades que ofrecen las instituciones, y por falta de interés en informarse, no acuden a ellas. Las redes están poco activadas con relación al potencial que disponen.

Figura 4. Gráfico de Relaciones por tipo - DO Méntrida y órganos institucionales.

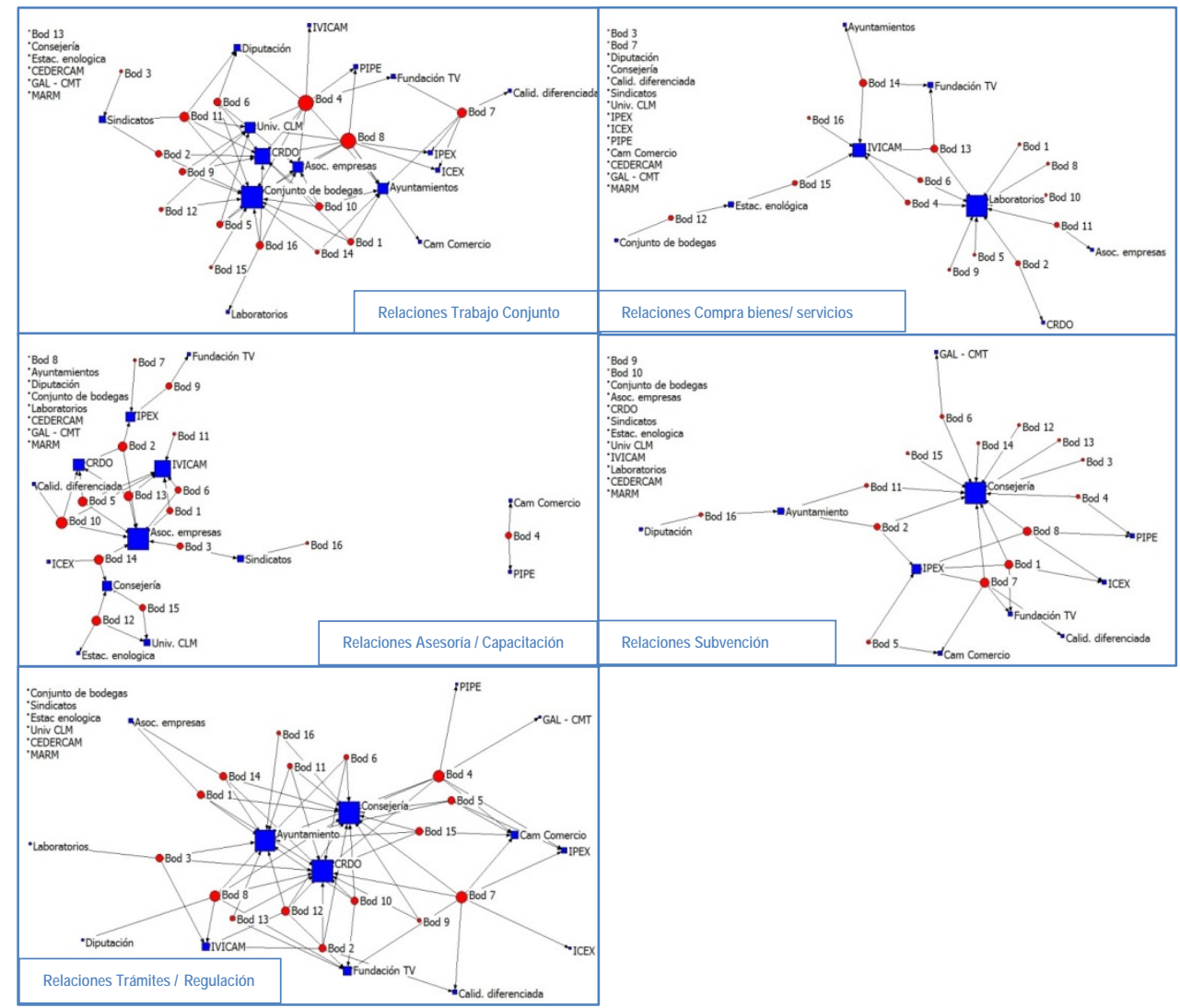

Fuente: Elaboración propia.

Por un lado hay un déficit por parte de las instituciones, que no demuestran interés en que los agentes del territorio conozcan las posibilidades que ofrecen, pero por otro, las bodegas tampoco se animan a conocerlo ni parecen tener disposición para 
establecer relaciones con las instituciones. El resultado de esta situación es el poco impacto que tiene en el territorio la presencia institucional, se perjudica el establecimiento de redes más estables y más dinámicas, ya que son éstas las que estructuran el territorio. Hay cierta distancia entre las redes que se podrían establecer, y las que realmente se concretan.

\subsection{LA DO MONDÉJAR}

\subsubsection{LA PERCEPCIÓN DE LA DO MONDÉJAR SOBRE SUS INSTITUCIONES}

En la entrevista con el CRDO de Mondéjar, se aprecia pesimismo y disconformidad. Con relación a las instituciones, el Consejo parece estar parcialmente contento con la actuación de la administración, pero también manifiestan algunas críticas a este respeto.

Destaca la gran disponibilidad de ayudas y subvenciones existentes, de las cuales intenta hacer uso de todas las posibilidades y opciones de financiación que le ofrecen (ayudas de comercialización, de marketing, de participación en ferias, de viajes, misiones inversas, etc.).

La crítica mayor recae sobre algunas políticas y medidas gubernamentales, nacionales y autonómicas, que perjudican el buen funcionamiento de la Denominación (imposibilidad de conservar formas tradicionales de producción vitivinícola, como las vendimias en familia y la pequeña propiedad familiar).

Se menciona también el alejamiento de las medidas y actuaciones de las instituciones autonómicas y nacionales de la realidad local.

No se mencionan ni se hacen referencias a las instituciones locales, a excepción de los ayuntamientos.

\subsubsection{LA PERCEPCIÓN DE LA DO MONDÉJAR SOBRE SI MISMA}

La entrevista revela que la visión del Consejo sobre la situación interna de la denominación es bastante pesimista. Fueron mencionados tres puntos que determinan el estado actual de la DO. Éstos constituyen sus principales amenazas, aunque también abarcan ciertos aspectos positivos sobre el impacto de la DO en el territorio.

El primer punto se relaciona con la situación del sector vitivinícola en la zona, si bien es cierto que los problemas están presentes en todos los sectores de la actividad agraria en esta zona: la falta de interés de los jóvenes en incorporarse, el abandono de los cultivos agrícolas y el arranque de viñedo. Como contrapunto positivo, se admite que la denominación es la responsable de la supervivencia de la vitivinicultura en la zona, y pese a todas las adversidades, es todavía un importante motor de la actividad agraria local.

El segundo punto, que constituye una de las mayores amenazas, es la baja motivación de los actores locales con la denominación de origen. Aunque la zona tenga cualidades muy especiales (clima, tradición, etc.), las bodegas locales no apuestan por la figura de calidad, y de las cinco empresas que iniciaron la DO, tres se 
dieron de baja. Actualmente la DO consta de solamente dos bodegas, y su dinámica está centrada sobre todo en la actuación de una de ellas: la más pionera y la que dirige el Consejo Regulador. La otra bodega, una cooperativa, intenta seguir sus pasos pese a sus limitaciones con la calidad final del producto, el cuidado en la elaboración del vino y sus estrategias de comercialización.

El tercer punto es la proximidad de la ciudad de Madrid a la zona, que ejerce un doble papel en la dinamización de Mondéjar: por un lado representa un importante mercado para sus productos, tanto en la venta local como en los propios canales de comercialización en la metrópoli, pero por otro ejerce cierta presión urbana, y atrae la población local a otros sectores de ocupación distintos del agrario.

\subsubsection{LAS BODEGAS DE LA DO MONDÉJAR Y SUS RELACIONES INSTITUCIONALES}

De las encuestas a bodegas, se extrae que los gráficos de relaciones obtenidos (Figura 6) no representan la realidad local identificada en el trabajo de campo. Aunque en el gráfico se puede distinguir que las dos empresas de la DO tienen comportamientos distintos, éstos no coinciden con la información proporcionada en la entrevista.

Figura 5. Red de Relaciones DO Móndejar y órganos Institucionales. Análisis de Redes Sociales (UCINET).

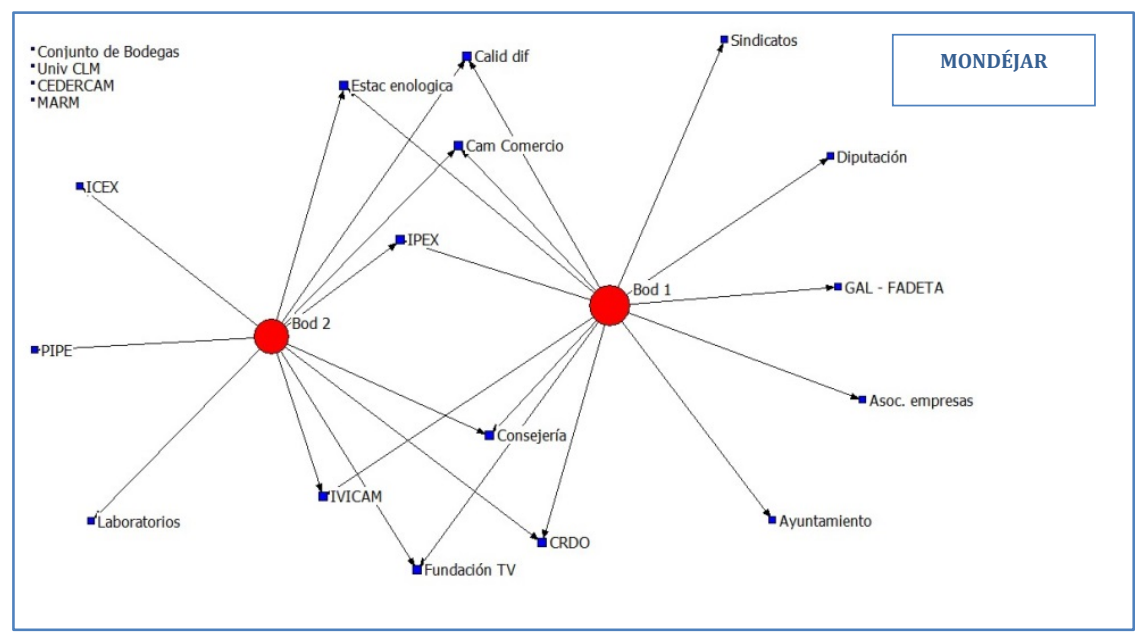

Fuente: Elaboración propia.

La empresa de carácter más innovador (bodega 1), que prima los vinos de calidad $\mathrm{y}$ apuesta por su presencia en los mercados, no es la que establece el mayor número de relaciones con los principales órganos vinculados a la exportación y producción de calidad (Figura 5). Por otro lado, la bodega 2 aparece muy bien relacionada con 
algunos de estos órganos, lo que contrasta con la información dada en la entrevista con el Consejo, que afirma que no exportan.

Figura 6. Gráfico de de Relaciones por tipo - DO Mondéjar y órganos institucionales.

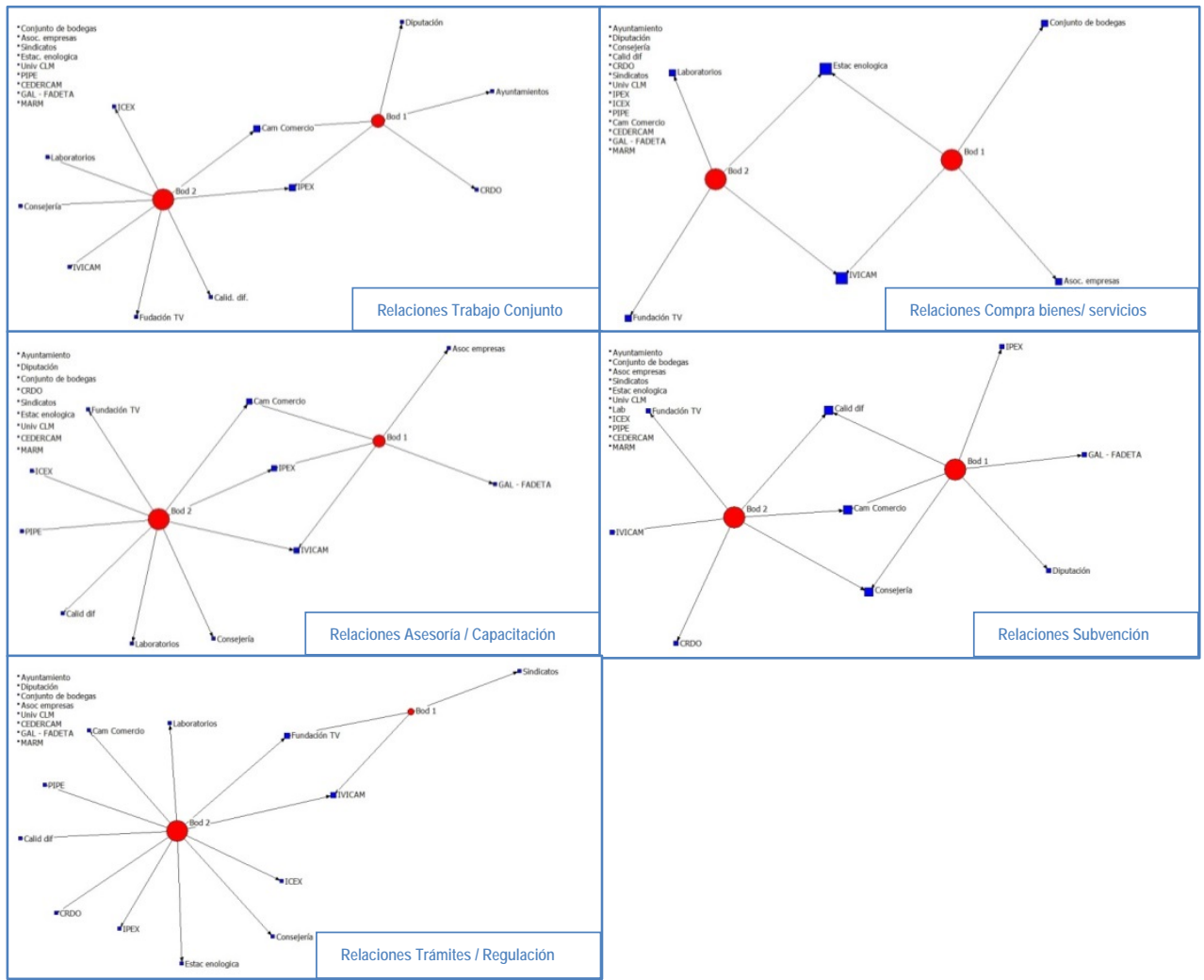

Fuente: Elaboración propia.

En la DO Mondéjar ocurre una situación similar que en la denominación de Méntrida: algunos órganos institucionales son percibidos con funciones diferentes de las que realmente ejercen, o se ignora parte de sus funciones. En los gráficos de la Figura 6, que cartografían las relaciones por tipo, se puede observar lo siguiente:

a) La Consejería está presente en las relaciones de trabajo conjunto, asesoría/capacitación y trámites/regulación de solamente una de las bodegas, siendo que la otra no ve en este órgano ninguna de estas funciones, aunque ambas empresas la relacionen a las subvenciones.

b) Al igual que en el caso de Méntrida, el IVICAM aparece en las relaciones de compra de bienes y servicios, aunque no sean sus funciones. Pero, al contrario de 
Méntrida, en este caso ambas bodegas también lo consideran dentro de sus relaciones de asesoría/capacitación, sus verdaderas funciones.

c) El Consejo Regulador figura en las relaciones de trabajo conjunto de solamente una de las bodegas, que coincide con aquella que preside el Consejo. Además, según los gráficos, la bodega menos activa de las dos, la cooperativa, establece un mayor número de relaciones de trabajo conjunto y asesoría/capacitación, lo que no se confirma en la realidad descrita en la entrevista.

Así como ocurre en Méntrida, las bodegas de Mondéjar tampoco se relacionan con las instituciones de la forma más efectiva, que dé respuesta a sus necesidades Esto también queda reflejado en la visión equivocada que tienen sobre las verdaderas funciones institucionales. El potencial dinamizador que podrían tener las instituciones en la DO queda reducido, tanto por la falta de interés institucional en divulgar las posibilidades de actuación que ofrecen, como por el escaso interés de las bodegas de la zona en informarse de ello. El impacto de la actuación institucional es limitado, y se configuran menos redes de lo que se podrían formar.

\subsection{LA DO UCLÉS}

\subsubsection{LA PERCEPCIÓN DE LA DO UCLÉS SOBRE SUS INSTITUCIONES}

En la entrevista con el Consejo Regulador de la DO Uclés, domina la insatisfacción con la actuación institucional con respecto al apoyo a la dinámica de la DO. Con referencia a la efectividad de las instituciones, el Consejo no percibe el efecto de las actuaciones institucionales en el territorio, y opina que las acciones propuestas no logran dar respuesta eficiente a muchas de las demandas de las denominaciones vitivinícolas. Estas insatisfacciones se manifiestan a través de una serie de críticas, aunque también son mencionados aspectos positivos de la actuación institucional. Se aludió con mucha frecuencia a los órganos institucionales de escala autonómica, y se han hecho pocas menciones a los órganos a escala local, cuya influencia en la dinámica de la DO es percibida como baja o prácticamente inexistente, a excepción de algunos ayuntamientos y de la diputación provincial.

La mayoría de las críticas expresadas están recogidas bajo la insatisfacción general acerca de la inadecuación de las políticas puestas en marcha a la realidad local, es decir, la distancia que detectan entre las políticas y actuaciones autonómicas y las necesidades sentidas por los actores de la zona. Esta crítica general se traduce en los siguientes aspectos:

a) En ocasiones, las ayudas concedidas suponen una cofinanciación inabordable por parte de la DO, mientras que las acciones más sencillas cuya cofinanciación sí es abarcable no están contempladas en los programas institucionales. También se manifiesta la necesidad de la existencia de algún fondo financiero que apoye a las Denominaciones pequeñas y de pocas posibilidades económicas en la cofinanciación de las subvenciones. 
b) Muchas de las ayudas disponibles son contradictorias o carecen de medidas complementarias. El principal ejemplo mencionado es sobre las ayudas de arranque y reestructuración de viñedo, que ponen en peligro el viñedo antiguo de la DO Uclés, el elemento diferenciador de esta DO, mencionado en su reglamento. También se hace referencia a las ayudas a la compra de maquinaria destinadas a aumentar la producción y adquirir mayores depósitos, sin que sean acompañadas de otras políticas en paralelo que apoyen la comercialización y promoción de toda esta producción incrementada. Esta misma filosofía de actuación es seguida por los programas de desarrollo rural que incurren en el mismo defecto.

c) Las ayudas y subvenciones no siempre son concedidas a los beneficiarios idóneos. Se ha tenido conocimiento de concesión de ayudas a jóvenes agricultores que tienen otras fuentes de ingresos, o de subvenciones a agricultores que están a punto de jubilarse.

d) En ocasiones, el coste de las acciones promovidas por las instituciones es alto, pero su impacto es bajo. Por ejemplo, el caso de las jornadas formativas ofrecidas por el IPEX, con un alto coste financiero y con muy baja asistencia por parte de las bodegas, en tanto que no consideran que esta formación tenga interés para la DO.

e) Existen muchas ayudas destinadas a las empresas individuales, pero pocas dedicadas a la DO en su conjunto, desatendiendo la demanda de apoyo a la acción colectiva que debe ser sostenida por la DO.

f) Hay cierta desconexión entre las políticas LEADER y PRODER puestas en marcha y las Denominaciones de Origen. Los Grupos de Acción Local (GAL) de la zona son poco accesibles, y hay dificultades por parte de la DO a la hora de realizar acciones conjuntas. Por ejemplo, proyectos intersectoriales de enoturismo y rutas del vino. Las bodegas intentan realizar actuaciones individuales en estas áreas, pero no se ha logrado ninguna acción colectiva.

g) Hay una falta de nexo y complementariedad entre las instituciones y sus políticas en materia de agricultura, industria y turismo, lo que se traduce en un desperdicio de recursos en muchas ocasiones. Un ejemplo de ello es el impacto visual de los aerogeneradores cerca del monasterio de Uclés, que son el resultado de políticas de energías renovables, pero que no tienen en cuenta su efecto negativo en este recurso turístico, histórico y paisajístico local.

En contraposición a las críticas mencionadas, se hace alusión a dos aspectos positivos:

a) La facilidad de interlocución con la Consejería de Agricultura, descrita como un órgano cercano, abierto a propuestas y negociaciones, y cuya proximidad puede ofrecer muchos beneficios.

b) La calidad del programa PIPE (Plan de Iniciación a la Promoción Exterior), valorado como bueno y completo, con capacidad para financiar hasta el $50 \%$ de gastos totales de las acciones y además ofrecer bolsas de viaje. 


\subsubsection{LA PERCEPCIÓN DE LA DO UCLÉS SOBRE SI MISMA}

La visión del Consejo Regulador sobre la situación de la DO revela diversos aspectos positivos, pese a que esta zona sufra de problemas semejantes a los citados por los demás Consejos, como el envejecimiento de los viticultores, la falta de interés de los jóvenes por la agricultura, la disminución del consumo de vino en las últimas décadas y la creciente competencia por precios de los vinos de países emergentes en el sector, como Chile, Argentina o Sudáfrica. En general, se considera que la existencia de la figura de calidad es una respuesta a medida, capaz de hacer frente a las dificultades que este territorio presenta.

Se define al conjunto de bodegas como un grupo motivado, que se moviliza para poner en marcha a la DO. Los vínculos entre los actores son bastante cercanos, hay una intensa colaboración entre ellos, y un cierto equilibrio entre sus relaciones de cooperación y competencia.

Otro aspecto a resaltar es el comportamiento innovador de las bodegas cooperativas de la DO Uclés, que se diferencia de aquellos de las demás DOs estudiadas, como se manifiesta en las respectivas entrevistas. Este comportamiento se traduce en dos aspectos principales: 1) parte de las ganancias de las cooperativas son invertidas en promoción; 2) todas las cooperativas de la zona cuentan con una página web con información sobre sus productos, y con un profesional encargado del control de la calidad de los vinos y de aspectos relacionados con su comercialización (en algunos casos son enólogos, y en otros bodegueros con formación específica). El perfil innovador se da por la fuerza del empuje que tienen las dos bodegas privadas de la zona, las fundadoras de la DO.

También se hace alusión a la baja proyección en el mercado de los vinos de la zona. Esto no se atribuye a la falta de calidad de sus vinos, que son ya reconocidos, sino a la juventud de la DO, que necesita ganar cuotas de mercado en otros territorios. El Consejo ve a la DO con buenas perspectivas de futuro, de ganar visibilidad en los siguientes años, y se consideran muy activos en la actualidad, buscando constantemente promocionarse y hacerse conocidos.

\subsubsection{LAS BODEGAS DE LA DO UCLÉS Y SUS RELACIONES INSTITUCIONALES}

El análisis de redes ha permitido observar las redes de relaciones construidas por los actores de la DO Uclés. Los gráficos obtenidos refrendan la percepción de la DO expresada en la entrevista, ya que en ellos queda reflejado que las bodegas están muy bien relacionadas, son activas, cada empresa se relaciona con determinados organismos según sus necesidades y tienen perfiles relativamente homogéneos, a excepción de la bodega 4 que no se relaciona con ninguno de los órganos de exportación (Figura 7). 
De la misma manera, en la Figura 7 se aprecia que las bodegas tienen una gran centralidad en relación con los órganos institucionales, al estar ubicadas en el centro de las relaciones.

Figura 7. Red de Relaciones DO Uclés y Órganos Institucionales. Análisis de Redes Sociales (UCINET).

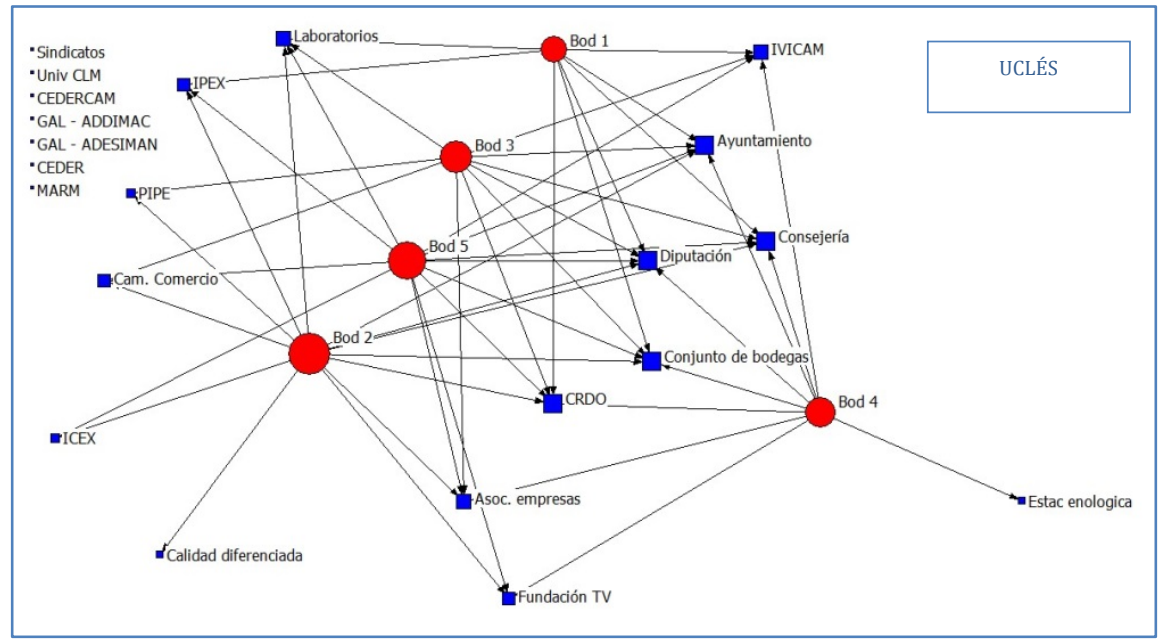

Fuente: Elaboración propia.

Los gráficos elaborados considerando solamente los tipos de relaciones (Figura 8), confirman el fenómeno ya mencionado en los gráficos de las DOs Méntrida y Mondéjar: no se atribuyen a las instituciones las funciones que verdaderamente tienen, o no se identifican sus principales funciones. Así, se repiten los comportamientos de los gráficos anteriores:

- $\quad$ El IVICAM está considerado como una figura importante en las relaciones de compra de bienes y servicios, y por otro lado es escasamente mencionado en las relaciones de formación y capacitación;

- La Consejería no está bien posicionada en el gráfico de relaciones de trabajo conjunto, aunque esté muy presente en las relaciones de trámites y subvenciones;

También al igual que en las DOs Méntrida y Mondéjar, el impacto de las instituciones en el territorio es reducido en relación con su potencial. Sin embargo, aunque que no se esté aprovechando al máximo la potencialidad de las instituciones, se observa que hay un mayor uso de la actuación institucional que se da sobre todo por las actividades de animación realizadas por el Consejo Regulador. En los gráficos de la Figura 8 se puede observar también el papel destacado que tiene la figura del gerente de la DO en la creación de redes y de territorio, lo que ha permitido un mejor aprovechamiento de los recursos disponibles en comparación con Méntrida y Mondéjar. 
Figura 8. Gráfico de Relaciones por tipo - DO Uclés y órganos institucionales.

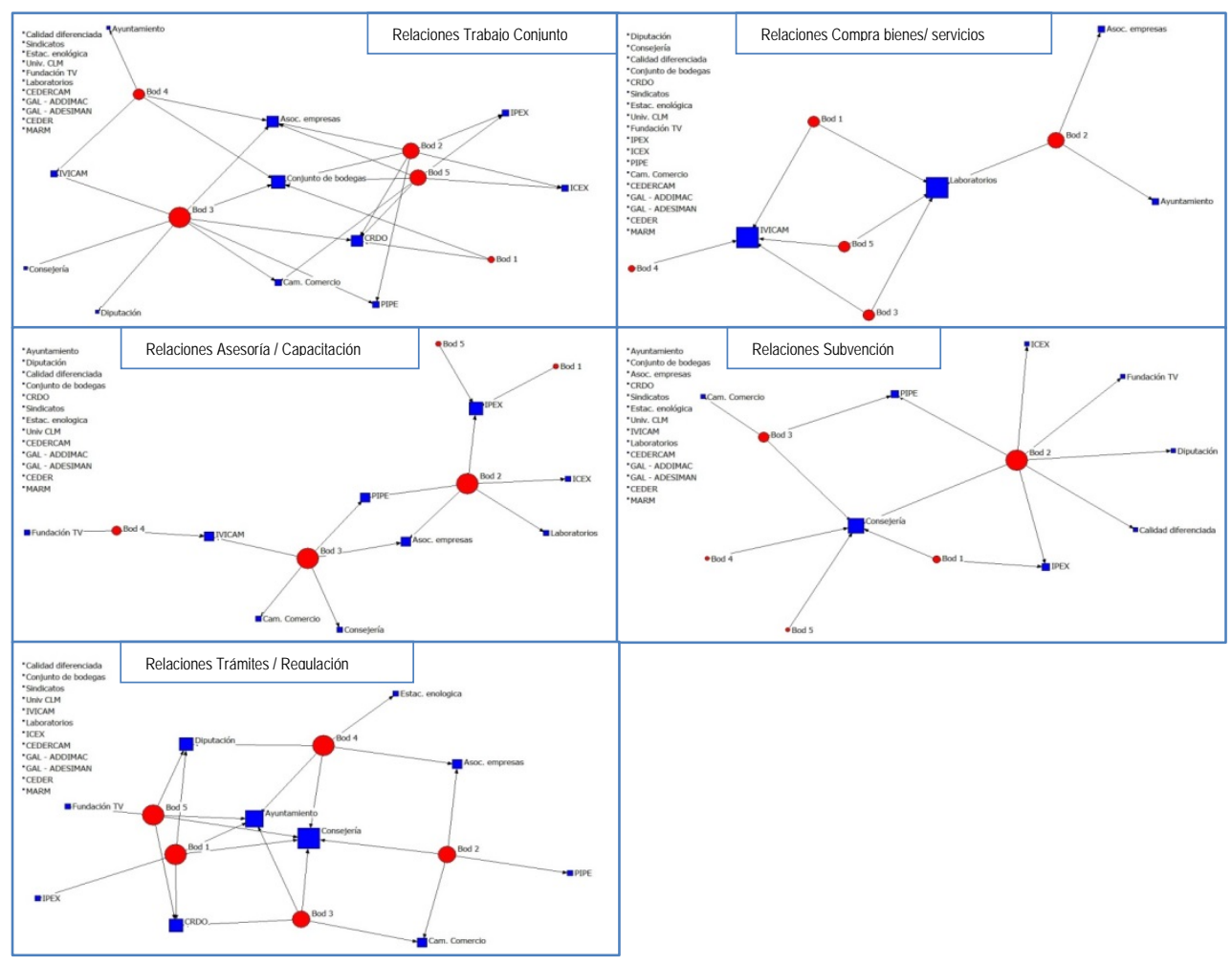

Fuente: Elaboración propia.

\subsection{LAS INSTITUCIONES}

\subsubsection{LA PERCEPCIÓN DE LAS INSTITUCIONES SOBRE SI MISMAS}

En la entrevista, las instituciones se describen a sí mismas considerando los siguientes aspectos:

a) Todos los órganos consideran que van más allá de dinamizar un sector productivo, y entienden sus funciones vinculadas a la idea de dinamizar un territorio. Este es el ejemplo del IPEX en tanto que entiende que consumir un producto con DO en el exterior lleva implícito consumir territorio, es decir, su cultura, sus productos, hacerles conocidos por su referencia territorial en el mercado exterior. La Consejería de Agricultura, en la misma línea considera que dinamiza el territorio al fomentar las marcas de calidad territorial.

b) Se definen como instituciones abiertas a la escucha del territorio, receptivas a las propuestas de los actores locales. Así, la Consejería busca participar 
en las convocatorias de los actores locales, aportando cierta oficialidad a estos eventos. A su vez el IVICAM entiende que toda su línea de investigación está enfocada a satisfacer las necesidades identificadas por parte de los agentes del sector.

c) Las instituciones creen atender las demandas generales del sector vitivinícola de la región que son bastante similares. En sus políticas y actuaciones, las instituciones consideran Castilla-La Mancha como un territorio relativamente homogéneo en relación con el estado evolutivo del sector productivo vitivinícola (condiciones de producción similares, calidad del vino comparable, condiciones sociales y económicas semejantes, etc), aunque admiten diferencias en la situación de cada área, y la existencia de necesidades específicas.

\subsubsection{LA PERCEPCIÓN DE LAS INSTITUCIONES SOBRE LAS DOS ESTUDIADAS}

La opinión que las cinco instituciones tienen sobre las Denominaciones de Origen estudiadas coincide en principalmente tres aspectos. En primer lugar, consideran las tres denominaciones diferentes, distinguiendo entre activas y pasivas. Pasivas son las DOs de Méntrida y Mondéjar, mientras que Uclés es considerada como activa. Méntrida y Mondéjar son vistas con poca participación y sin aprovechar los recursos ofrecidos por las instituciones para su desarrollo.

El segundo aspecto se refiere a una realidad común del sector vitivinícola de las tres zonas, ya que todas las DOs son consideradas inmovilistas, con viticultores de edad avanzada y baja incorporación de jóvenes a la actividad, dedicación parcial al viñedo y predominancia de cooperativas con un perfil de venta en graneles. Es decir, las tres DOs se insertan en zonas rurales difíciles, y las bodegas no cuentan con un contexto dinámico; además, las instituciones reconocen las dificultades existentes para que estas bodegas prosperen en el contexto social en el que están insertas. Sin embargo, Uclés se diferencia de esta visión inmovilista por su mayor capacidad de acción colectiva.

El tercer y último aspecto consiste en la falta de capacidad de los actores de las DOs de aprovechar los recursos ofrecidos por las instituciones para su desarrollo. El IVICAM incide especialmente en este problema resaltando que todas estas Denominaciones no aprovechan ni siquiera sus propios recursos, pese a gozar de condiciones naturales excelentes como los suelos o el clima, base para la diferenciación. Como afirma el IVICAM, "Mondéjar no es como Rueda, o Méntrida como Ribera, porque no lo han querido ser, porque tienen todos los elementos para el mismo éxito".

\subsubsection{FORMACIÓN DE REDES ENTRE LAS INSTITUCIONES}

Todas las instituciones entrevistadas están conectadas entre sí en lo que se refiere a los aspectos organizativos, ya que todas ellas forman parte de las estructuras de la administración de la Junta de Castilla-La Mancha, además de compartir espacio en una misma institución, la Fundación Tierra de Viñedos. 
Tabla 5. Fichas informativas de las Instituciones entrevistadas.

\begin{tabular}{|c|c|c|c|}
\hline Institución & $\begin{array}{l}\text { Organización / } \\
\text { Estructura }\end{array}$ & Funciones y Objetivos & $\begin{array}{l}\text { Participación de } \\
\text { actores locales / sector }\end{array}$ \\
\hline $\begin{array}{l}\text { Consejería de } \\
\text { Agricultura - } \\
\text { Junta de Castilla- } \\
\text { La Mancha. } \\
\text { Dirección } \\
\text { General de } \\
\text { Infraestructuras y } \\
\text { Desarrollo Rural } \\
\text { (DGIDR), } \\
\text { Servicio de } \\
\text { Ordenación } \\
\text { Alimentaria y } \\
\text { Servicio de } \\
\text { Calidad Diferen- } \\
\text { ciada }\end{array}$ & $\begin{array}{l}\text { DGIDR: órgano de } \\
\text { gestión de la Conse- } \\
\text { jería de Agricultura, y } \\
\text { opera a través del } \\
\text { Servicio de Ordena- } \\
\text { ción Alimentaria y del } \\
\text { Servicio de Calidad } \\
\text { Diferenciada. }\end{array}$ & $\begin{array}{l}\text {-Gestión de ayudas } \\
\text { comunitarias } \\
\text { (FEADER) } \\
\text {-Reconocimiento y } \\
\text { modificaciones de } \\
\text { figuras de calidad } \\
\text {-Reconocimiento de } \\
\text { órganos de gestión de } \\
\text { figuras de calidad } \\
\text {-Ayudas a la participa- } \\
\text { ción, información y } \\
\text { promoción figuras de } \\
\text { calidad: Plan de Desa- } \\
\text { rrollo Rural (PDR) }\end{array}$ & No hay \\
\hline $\begin{array}{l}\text { Instituto de la Vid } \\
\text { y el Vino de } \\
\text { Castilla-La } \\
\text { Mancha } \\
\text { (IVICAM) }\end{array}$ & $\begin{array}{l}\text { Organismo autónomo } \\
\text { adscrito a la Consejer- } \\
\text { ía de Agricultura, } \\
\text { financiación privada } \\
\text { (sanciones y tasas del } \\
\text { sector) }\end{array}$ & $\begin{array}{l}\text { Desarrollo del sector } \\
\text { vitivinícola de la } \\
\text { Comunidad Autónoma: } \\
\text { investigación y forma- } \\
\text { ción. }\end{array}$ & $\begin{array}{l}\text { Vocales (representantes } \\
\text { del sector) en el Conse- } \\
\text { jo Asesor (órgano } \\
\text { consultivo). }\end{array}$ \\
\hline $\begin{array}{l}\text { Instituto de } \\
\text { Promoción } \\
\text { Exterior de } \\
\text { Castilla-La } \\
\text { Mancha (IPEX) }\end{array}$ & $\begin{array}{l}\text { Organismo pertene- } \\
\text { ciente a la Junta de } \\
\text { Comunidades de } \\
\text { CLM, adscrito a la } \\
\text { Consejería de Empleo } \\
\text { y Economía. }\end{array}$ & $\begin{array}{l}\text { Internacionalización de } \\
\text { las empresas castellano- } \\
\text { manchegas y captación } \\
\text { de inversiones extranje- } \\
\text { ras hacia la región. }\end{array}$ & $\begin{array}{l}\text { Vocales (representantes } \\
\text { de diferentes colectivos } \\
\text { de actores) en el } \\
\text { Consejo de Administra- } \\
\text { ción y en el Consejo } \\
\text { Asesor. }\end{array}$ \\
\hline $\begin{array}{c}\text { Fundación } \\
\text { Castilla-La } \\
\text { Mancha Tierra de } \\
\text { Viñedos (FTV) }\end{array}$ & $\begin{array}{l}\text { Organismo privado, } \\
\text { cuya gestión cuenta } \\
\text { con participación de } \\
\text { Administración, } \\
\text { financiado por cuota } \\
\text { obligatoria pagada por } \\
\text { miembros adscritos a } \\
\text { la DO. }\end{array}$ & $\begin{array}{l}\text {-Promoción e imagen: } \\
\text { mercados nacionales e } \\
\text { internacionales, crear } \\
\text { una imagen de notorie- } \\
\text { dad. } \\
\text {-Intermediación: } \\
\text { relaciones comerciales, } \\
\text { conocimiento de } \\
\text { mercados. } \\
\text {-Dinamización y } \\
\text { desarrollo }\end{array}$ & $\begin{array}{l}\text { En el patronato, a través } \\
\text { de vocales (represen- } \\
\text { tantes del sector) }\end{array}$ \\
\hline
\end{tabular}

Fuente: Elaboración propia. 
Las cuatro instituciones entrevistadas desempeñan cada una un papel, pero no de manera coordinada entre las cuatro. Aunque en ocasiones hay intervenciones puntuales coordinadas entre dos o más de ellas, no se ha creado una verdadera red institucional. Cada institución tiene funciones diferentes, como indica la Tabla 5, que pueden resultar complementarias y crear sinergias de cara a la vitivinicultura.

Todos los órganos institucionales entrevistados afirman no tener más que colaboraciones puntuales con las demás instituciones presentes en el territorio.

\section{EL APOYO INSTITUCIONAL A LAS DENOMINACIONES DE ORIGEN: ANÁLISIS DE RESULTADOS}

A partir de toda la información obtenida, al comparar las diferentes visiones de los distintos actores, el aspecto que más llama la atención es la discrepancia de visiones sobre el papel que tiene el tejido institucional en el apoyo a la actividad de las denominaciones de origen.

En general, las bodegas y los Consejos perciben la actuación de las instituciones alejadas de la realidad y necesidades sentidas por éstos. A su vez, las propias instituciones no perciben sus actuaciones distantes de lo que los agentes locales esperan de ellas.

Se destacan cuatro aspectos que son capaces de explicar, en parte, algunas de estas discrepancias: la inadecuación de las políticas de rango regional a la realidad local; la frágil capacidad de movilización y acción colectiva de las denominaciones de origen; la falta de apertura institucional a la participación de los actores locales; y la débil complementariedad de las actuaciones institucionales de las mismas o de diferentes áreas.

\subsection{LA INADECUACIÓN DE LAS POLÍTICAS DE RANGO REGIONAL A LA REALIDAD LOCAL}

Los Consejos Reguladores y bodegas manifiestan insatisfacción por el apoyo institucional a sus actividades, y la falta de comprensión de sus políticas y medidas, que entienden que no favorecen a los que las necesitan realmente. Pese a que consideran que son instituciones de cierto peso, y que tienen presencia en el territorio, lo conciben como una "presencia equivocada", que en muchas ocasiones puede provocar más pérdidas que beneficios, alterando el orden local, dificultando procesos burocráticos y no actuando en los ámbitos que sí consideran necesarios.

Las instituciones entrevistadas creen estar cumpliendo adecuadamente con sus objetivos y funciones, y creen aportar beneficios a las denominaciones de origen castellano-manchegas a través de sus actuaciones. Justifican sus actuaciones desde de una visión holística de la región castellano-manchega, sin tener la pretensión de atender especificidades locales. Las actuaciones institucionales no tienen el impacto deseado porque éstas no conocen verdaderamente los problemas y necesidades de las denominaciones de origen. Se aprecia una falta de conocimiento de las estrategias de 
las DOs, y un desajuste entre los aspectos en los que las instituciones ponen los apoyos, y aquellos que más favorecen o necesitan las DOs.

Esta discrepancia entre las ayudas y políticas institucionales y la realidad local de las denominaciones de origen requiere la actuación de un intermediario que hiciera llegar las demandas específicas locales a las instituciones regionales, en la elaboración de sus políticas y actuaciones. Los Consejos Reguladores parecen no tener fuerza suficiente para influir en las políticas de rango regional. Este trabajo de intermediación puede ser ejercido por las comarcas, o por las Diputaciones, o incluso por el propio Consejo Regulador, si se les concediera fuerza política suficiente para tal. Según se ha constatado en este estudio, hasta el momento presente no hay ninguna figura con presencia ni fuerza suficiente para ejercer de intermediario, aunque esta figura favorecería el ajuste de las políticas regionales.

\subsection{LA FRÁGIL CAPACIDAD DE MOVILIZACIÓN Y ACCIÓN COLECTIVA DE LAS DENOMINACIONES DE ORIGEN}

Tanto las instituciones como los propios Consejos Reguladores reconocen fragilidades en la capacidad de movilización de los actores locales. Sin embargo, a partir del discurso de los Consejos Reguladores se observan diferencias en las situaciones de cada denominación de origen. La DO Uclés es la que presenta el perfil más dinámico dentro de las tres denominaciones estudiadas. Las DOs Méntrida y Mondéjar manifiestan claramente importantes carencias en lo referente a la dinamización colectiva.

Al ser más dinámica, Uclés presenta una mayor capacidad de conseguir beneficios de las actuaciones institucionales, pues tienen mejores conexiones y relaciones con las instituciones. Un papel importante en estas mejores conexiones se asocia a la figura de la propia gerencia del CRDO, que cumple una función de animador del territorio. Pese a esto, estas conexiones todavía son mejorables, y aún le falta a la DO Uclés la posibilidad de tener más peso frente a las decisiones de las instituciones regionales. En este sentido, en la DO Uclés influye más la cohesión interna de los actores de la denominación, que el apoyo que puedan recibir por parte de las instituciones.

\subsection{LA FALTA DE APERTURA INSTITUCIONAL A LA PARTICIPACIÓN DE LOS ACTORES LOCALES}

Las instituciones se describen a sí mismas como abiertas a la participación y representación de los actores locales de los sectores y áreas en las que actúan. Sin embargo, los actores de las denominaciones de origen no se sienten adecuadamente representados en ellas, ni encuentran la vía de participación en las decisiones institucionales.

Aunque todas las instituciones entrevistadas afirman establecer vías de participación de los actores locales en sus decisiones, que incluso están reflejados en 
sus estructuras organizativas, dichas vías resultan ser insuficientes porque llevan a una escasa representatividad de cada DO en un escenario vitivinícola tan extenso como el de Castilla-La Mancha.

Las estructuras institucionales de participación existentes en la actualidad se han mostrado inadecuadas, y hasta el presente momento no se han abierto nuevas estructuras que permitan una apropiada representatividad de las denominaciones de origen en sus procesos decisorios, posibilitando un acercamiento de las políticas y actuaciones institucionales a las necesidades locales.

\subsection{LA DÉBIL COMPLEMENTARIEDAD DE LAS ACTUACIONES INSTITUCIONALES}

El tejido institucional castellano manchego es denso. Sin embargo, a pesar de esta densidad se aprecia que las actividades que desarrolla cada institución no alcanzan una complementariedad ni son capaces de promover sinergias.

En el mundo del vino de calidad, la complementariedad entre instituciones del mismo sector, así como de sectores relacionados, como el turismo, el medio ambiente o el empleo son importantes. En las denominaciones estudiadas, además de no existir dicha complementariedad, muchas veces las políticas institucionales llegan a producir interferencias negativas entre ellas, o pueden ser incluso contradictorias, confundiendo los actores locales.

Existen algunas interacciones entre los órganos que componen el tejido institucional castellano-manchego, pero éstas se dan más bien a nivel organizativo, pues estos órganos pertenecen a una dirección del gobierno o están en contacto a través de la Administración. Estas interacciones se han mostrado insuficientes para garantizar la orquestación de sus políticas y actuaciones, sobre todo en lo que se refiere a órganos de diferentes sectores.

\section{CONCLUSIONES}

De todo lo expuesto anteriormente se pueden extraer las conclusiones siguientes:

1. El enfoque constructivista adoptado ha resultado pertinente para entender la distancia entre las visiones de las DOs y de las instituciones sobre la realidad estudiada y sobre ellas mismas.

2. Las actuaciones institucionales no parecen haber favorecido la plena activación del recurso vitivinícola en las tres denominaciones estudiadas, pese al importante peso que esta actividad desempeña en la Comunidad Autónoma de Castilla la Mancha. Las instituciones no son capaces de acompañar las dinámicas colectivas que se establecen en el seno de estas figuras, ni de promover su dinamización, acorde con sus capacidades y medios de los que disponen. A su vez por falta de conocimiento e interés, las denominaciones esperan de las instituciones actuaciones que no están dentro de su ámbito de actuación ni son de su competencia. 
3. En ninguna de las tres denominaciones estudiadas se ha logrado por completo la participación activa de todos los agentes involucrados, sean públicos o privados. Esta situación no ha permitido identificar procesos de gobernanza territorial.

4. La inadecuación de las políticas de rango regional a la realidad local, la frágil capacidad de movilización y acción colectiva de las denominaciones de origen, la falta de apertura institucional a la participación de los actores locales y la débil complementariedad de las actuaciones institucionales, indican que todavía se está lejos de esa gobernanza territorial, en la que las relaciones entre las DOs e instituciones se apoyen en una dinámica colectiva compartida, que es la que promueve la construcción del territorio.

5. El estudio de las tres Denominaciones pone de relieve que la realidad es diversa, y las diferentes zonas no se comportan de la misma manera. La DO Uclés manifiesta una dinámica colectiva más sólida que las otras, asociada a la presencia del papel que juega la gerente de la denominación como "animadora social" dentro y fuera del territorio DO.

6. Todas las denominaciones han conseguido la cualificación de su producto, pero no siempre esta cualificación del producto se ha traducido en una cualificación del territorio, aunque Uclés destaque respeto a las otras.

Los resultados también indican que la existencia de mejores mecanismos de comunicación y participación entre los órganos institucionales en la elaboración de políticas y evaluación de actuaciones podría propiciar la gobernanza local y especialmente la gobernanza territorial.

Es bien sabido que uno de los instrumentos de apoyo a las DOs son las políticas que ponen en marcha las instituciones, particularmente las de rango autonómico, pero estas políticas deben tener una visión holística y beneficiar a la diversidad de actores vinculados a la figura de calidad y facilitar la interacción de instituciones tanto del sector (agricultura y alimentación) como de otros ámbitos como el turismo, la cultura, la educación, o la industria.

Las políticas, a su vez para ser verdaderamente eficaces han de promover actuaciones apropiadas para cada tipo de DO existente, ya que las demandas varían considerablemente entre DOs más o menos arraigadas, más o menos nuevas, más grandes o más pequeñas. Es la territorialización de estas políticas la que puede promover un verdadero desarrollo rural. 


\section{BIBLIOGRAFÍA}

CAMAGNI, R. Ed. (1991). Innovation networks. Spatial pespectives. London, GREMI-Belhaven Press.

CARAVACA, I., GONZÁLEZ, G. (2009). Las redes de colaboración como base del desarrollo territorial. Scripta Nova. Revista Electrónica de Geografía y Ciencias sociales. Barcelona: Universidad de Barcelona, vol. XIII, núm. 289. Disponible en: http://www.ub.es/geocrit/sn/sn-289.htm

CASTI, J.L. (1995). The Theory of Networks. En Basten, D., Casti, J. y Thord, R. (eds.): Networks in Action. Communication, Economics and Human Knowledge. Berlin, Springer, 3-24.

COOKE, P., MORGAN K. (1993). The network paradigm: new departures in corporate and regional development. Environment and Planning D: Society and Space, 11(5), $543-564$.

FONTE, M. (2000). Tradiciones y nuevos modelos de ruralidad en las regiones del. Mediterráneo. Estudos Sociedade e Agricultura,15, 147-157.

HERNANDEZ DE LA CRUZ, L.A. (2011). Geografía de los territorios rurales. Notas para su análisis. Revista Catalana de Geografia [online],IV època / volum XVI / núm. 42 / abril 2011. Disponible en: http://www.rcg.cat/articles.php?id=203

KOSCHATZKY, K. (2002). Fundamentos de la Economía de Redes. Especial Enfoque a la Innovación. Revista Economía Industrial, 346, 15-26.

LAZAREV,G. (2009). Promouvoir le développment des territoires ruraux. En. CIHEAM et Plan Bleu, MediTERRA 2009. Presses de Sciences Politiques. Annuels, 2009/1, 183-210.

LINDÓN, ALICIA. (2007). El constructivismo geográfico y las aproximaciones cualitativas. Revista de geografía Norte Grande, 37, 5-21. Recuperado en 27 de septiembre de 2013, de

http://www.scielo.cl/scielo.php?script=sci_arttext\&pid=S0718$34022007000100001 \& \operatorname{lng}=$ es\&tlng=es. $10.4067 /$ S0718-34022007000100001.

MÉNDEZ, R. (2002). Innovación y desarrollo territorial: algunos debates teóricos recientes, Revista EURE, Santiago de Chile, vol. XXVIII, 84, 63-83.

ROMAGOSA, F., EAGLES, P. F.J., BUTEAU DUITSCHAEVER, W. (2012). Evaluación de la gobernanza en los espacios naturales protegidos. El caso de la Columbia Británica y Ontario (Canadá). Anales de Geografía, vol. 32, 1, 133-151.

ROMERO, J., FARINOS, J. (2011). Redescubriendo la gobernanza más allá del buen gobierno. Democracia como base, desarrollo territorial como resultado. Boletín de la Asociación de Geógrafos Españoles, 56, 295-319.

SALOM, J. y ALBERTOS, J.M. (eds.) (2009). Redes socioinstitucionales, estrategias de innovación y desarrollo territorial en España. Valencia, PUV, Universitat de València, 99-130.

SANZ CAÑADA, J. (2009). Calificación de productos, externalidades territoriales y gobernanza territorial: las denominaciones de origen. Conferencia plenaria del IV 
Congreso Internacional de la Red SIAL "Alimentación, Agricultura Familiar y Territorio" ALFATER. Mar del Plata (Argentina), 27 al 31 de Octubre de 2008

SCHEJTMAN, A., BERDEGUÉ, J .A. (2004). Desarrollo territorial rural. RimispCentro Latinoamericano para el Desarrollo Rural. Santiago, Chile.

SCHEJTMAN, A., E. RAMÍREZ (2004). Desarrollo territorial rural. Aspectos destacados de experiencias en proceso en América Latina. Lima, Perú, Ed. Fondo Mink'a de Chorlaví.

VANDECANDELAERE, E., ARFINI, F., BELLETTI, G., MARESCOTTI, A. (2010). Uniendo personas, territorios y productos. Guía para fomentar la calidad vinculada al origen y las indicaciones geográficas sostenibles. Strengthening International Research on Geographical Indications (SINER-GI) 194 p. Disponible en http://www.fao.org/docrep/013/i1760s/i1760s00.htm 